\title{
Sobre el imperialismo lingüístico y el idioma inglés
}

Ana María Martínez Mendoza

\begin{abstract}
... [nuestro] trabajo [como profesores de inglés], aparentemente insignificante, puede bacer la diferencia en un mundo que necesita de una comunicación que trascienda los intereses y las fronteras nacionales.'
\end{abstract}

El presente ensayo no pretende ni un análisis exhaustivo ni una detallada investigación del tema. Es más una reflexión sobre la responsabilidad y las implicaciones que la enseñanza del inglés como idioma extranjero impone a todas aquellas personas involucradas en su quehacer en los países latinoamericanos como el nuestro en esta etapa neoliberal del capitalismo, en la que, con una arrogancia y prepotencia desmedidas, intenta imponer su forma de producción que incita a un consumismo desmedido de nefastos resultados ecológicos, su sistema de signos (o simbolismos), sus dinámicas de poder y su arrogancia étnica-cultural irrespetando y menoscabando la riqueza multicultural y multilingüe de cada una de las naciones y grupos socioculturales que conforman a la humanidad actual.

La reflexión fue suscitada por las sugerentes conferencias El Imperialismo lingüistico y el Idioma Inglés y El Inglés como un Idioma Mundial: Actitudes Internacionales, que el socio-lingüista Joseph Boyle, amplio conocedor del tema, dictó en la Universidad Centroamericana.

Sobre el imperialismo lingüistico y el idioma inglés 
Para comenzar, señalaré algunos aportes básicos de la lingüística, la sociolingüística, y de ciencias afines, así como los fundamentos teóricos elementales contemporáneos sobre ELT, siglas en inglés para la Enseñanza del Idioma Inglés, tarea en la que, por razones de espacio y del contenido mismo de la reflexión, no profundizaré. Los temas referidos serán tratados en la forma más simple posible, pudiendo resultar esto en algunas imprecisiones teóricas, por las que me disculpo de antemano. A continuación, presentaré algunas opiniones sobre la expansión del idioma inglés y sus repercusiones. Finalizaré haciendo un breve resumen de la ideas principal de las conferencias del doctor Boyle. Esto servirá de criterio para comprender la relación que existe entre una enseñanza del inglés y la promoción de los bastiones del neoliberalismo con su uso "imperial" y entre una opción hacia una enseñanza liberadora, de corte innovador que posibilite a los hablantes de este idioma como idioma extranjero, establecer interacciones lingüísticas más equitativas que apuesten a respetar la riqueza cultural y la modalidad lingüística propia de cada pueblo marginado por el neoliberalismo.

\section{Visiones teóricas generales}

Entre los aportes esenciales de la lingüística, la sociolingüística y ciencias afines que ayudan a comprender la crítica a los intentos de imperialismo lingüístico del idioma inglés, encontramos:

1. La arbitrariedad y la convencionalidad del lenguaje, entendiéndose por arbitrariedad, el hecho de que los fonemas del lenguaje fueron "casual, creativa o arbitrariamente" reunidos por diversos grupos humanos para designar los objetos del mundo que les rodeaba (lo que más tarde incluyó procesos de abstracción del lenguaje entre significante y significado más elaborados); y por convencionalidad, la aceptación dentro de un área geográfica común por una comunidad de hablantes específica de la relación entre los fonemas y los objetos designados por los mismo, los que, por su uso y con el tiempo se han convertido en los diferentes conceptos utilizados por cada idioma del planeta.

2. A medida que las ciencias humanísticas fueron desenmascarando las relaciones de superioridad y de subordinación encubiertas en el lenguaje por las ideologías dominantes en turno, surgieron los términos de gramática prescriptiva, contrapuesto al de gramática descriptiva, 
al reconocerse que el sistema de signos (o simbolismo) operante era determinado por quienes ostentaban (y ostentan) su poderio en cada estadio histórico. Hasta hace muy poco tiempo (y habría que cuestionarse el hace) los binomios de correcto e incorrecto, propio o impropio, adecuado o inadecuado, culto y vulgar, daban (caún lo hacen?) su aprobación a lo dictaminado o bablado por las minorías, y por supuesto, estaban cargados de fuerte desaprobación hacia lo expresado por las mayorías. Examinando el asunto más cuidadosamente, es pertinente indagar sobre los orígenes sociales de tal prescripción, a la que en adelante me referiré como estándar. Como lo menciona el mundialmente reconocido lingüista David Crystal, "[estos orígenes] de la noción de 'estándar' son evidentes en las definiciones del término en los diccionarios, verbigracia, ' algo establecido por la autoridad, la costumbre o el consentimiento general como un modelo o ejemplo' (Diccionario Longman del idioma inglés). De hecho, la sociedad le confiere o sanciona estatus al estándar de algo, de donde adquiere el sentido secundario de 'un grado de cualidad o de valor' que, a cambio, resulta en los usos peyorativos de 'no estandarizado' y 'sub estandarizado'"2. De ahí que, ante tal revelación, al pasar de una gramática transformativa a una generativa, no sólo se reconoció como aceptable y objeto de estudio el lenguaje dominante, sino también se incorporó el lenguaje de las mayorías al estudio gramatical. Como resultado, hoy en día se conoce como gramática prescriptiva, (estándar) como su nombre lo indica, la prescrita por las minorías cultas, las que por medio de sus Reales Academias de la Lengua, sus diccionarios, etc., prescriben impositivamente cómo deben hablarse los idiomas propiamente. Como contraparte, se llama gramática descriptiva a la descripción y estudio del lenguaje utilizado por las mayorías, frecuentemente iletradas o con mínimo acceso a la educación, quienes continúan y continuarán utilizando el idioma de la mejor manera posible pues recordemos que son la arbitrariedad y la convencionalidad inherentes en el mismo las que han creado los conceptos usados para nombrar a la realidad (cualesquier concepto que de esta se tenga), hablar de ella y por que no, posibilitar su subsistencia.

3. No olvidemos que quienes históricamente han impuesto su sistema de signos con el que mantienen y promueven su hegemonia, con sus privilegios y libertades resultantes, son las minorías. Para ilustrar este punto en un contexto actual, Bourdieu, Galeano y Canclini, 
entre otros, explican cómo el neoliberalismo ha intentado imponer su sistema de signos.

Según Bourdieu, el mito de la "mundialización" global dominante obtiene su fuerza del DISCURSO DOMINANTE, ya que existe "todo un trabajo de inculcación simbólica en el que tanto los intelectuales como los ciudadanos simples participan, los primeros muy activamente, muy pasivos los segundos. $\mathrm{Y}$ es este uno de los grandes métodos para difundir e inculcar esa visión del mundo. De esta forma imponen su legitimidad a una visión neoliberal que justifica con racionalizaciones económicas los presupuestos más clásicos del pensamiento conservador de todas las épocas y geografías". ${ }^{3}$

Eduardo Galeano es mucho más explícito. En su libro Patas Arriba leemos:

\section{El Lenguaje}

En la época victoriana, no se podían mencionar los pantalones en presencia de una señorita. Hoy por hoy, no queda bien decir ciertas cosas en presencia de la opinión pública:

el capitalismo luce el nombre artístico de economía de mercado;

el imperialismo se llama globalización;

las victimas del imperialismo se llaman paises en vias de desarrollo, que es como llamar niños a los enanos;

el oportunismo se llama pragmatismo ;

la traición se llama realismo;

los pobres se llaman carentes, o carenciados, o personas de escasos recursos;

la expulsión de los niños pobres por el sistema educativo se conoce bajo el nombre de deserción escolar;

el derecho del patrón a despedir al obrero sin indemnización ni explicación se llama flexibilización del mercado laboral;

el lenguaje oficial reconoce los derechos de las mujeres, entre los derechos de las minorias, como si la mitad masculina de la humanidad fuera la mayoría; 
en lugar de dictadura militar, se dice proceso;

las torturas se llaman apremios ilegales; o también presiones físicas o psicológicas; cuando los ladrones son de buena familia, no son ladrones sino cleptómanos;

el saqueo de los fondos públicos por los políticos corruptos responde al nombre de enriquecimiento ilícito;

se llaman accidentes los crímenes que cometen los automóviles;

para decir ciegos, se dice no videntes;

un negro es un hombre de color;

donde dice larga y penosa enfermedad, debe leerse cáncer o sida;

repentina dolencia significa infarto;

nunca se dice muerte, sino desaparición física;

tampoco son muertos los seres humanos aniquilados en las operaciones militares: los muertos en batalla son bajas, y los civiles que se la ligan sin comerla ni beberla, son daños colaterales;

en 1995, cuando las explosiones nucleares de Francia en el Pacífico sur, el embajador francés en Nueva Zelanda declaró: «No me gusta esa palabra bomba. No son bombas. Son artefactos que explotan»;

se llaman Convivir algunas de las bandas que asesinan gente en Colombia, a la sombra de la protección militar;

Dignidad era el nombre de uno de los campos de concentración de la dictadura chilena y Libertad la mayor cárcel de la dictadura uruguaya.

se llama Paz y Justicia el grupo paramilitar que, en 1997, acribilló por la espalda a cuarenta y cinco campesinos, casi todos mujeres y niños, mientras rezaban en una iglesia del pueblo de Acteal, en Chiapas. ${ }^{+}$

¿Y que hay de la expresión combate al terrorismo, tan ampliamente utilizada en los discursos del presidente Bush y del mandatario salvadoreño en la última cumbre centroamericana sobre la integración y los tratados de libre comercio? ¿Quién define qué es terrorismo, contra quien, para qué y por qué se utiliza esa expresión? 
Por su parte, Néstor García Canclini, en su libro Globalización Imaginada presenta dos concepciones de la globalización, a saber, una que puede ser vista como un conjunto de estrategias para realizar la hegemonía de macro empresas industriales, corporaciones financieras, majors del cine, la televisión, la música, la informática, con el objetivo de apropiarse de los recursos naturales y culturales del trabajo, del ocio, y del dinero [¿Y por qué no de las conciencias?] de los países pobres, subordinándolos a la explotación concentrada con que esos actores reordenaron el mundo en la segunda mitad del siglo XX. Y la otra globalización que es también un horizonte imaginado por sujetos colectivos e individuales, o por gobiernos y empresas de países dependientes, por realizadores del cine, etc. a fin de reinsertar sus productos en mercados más amplios. Canclini explica que las políticas de globalización logran consenso en parte porque sus DISCURSOS estimulan la imaginación de millones de personas con sus promesas. Esto implica que muchos de los relatos sobre lo que les ha sucedido a quienes supieron adaptar sus bienes, sus mensajes y sus operaciones financieras para reubicarse en territorios expandido, indican que el realismo de lo local, de quienes se conforman con sumar cifras nacionales, se habría vuelto una visión miope. Habría que preguntarse cuánto de imaginario hay en esta visión de la ampliación del horizonte local y nacional. ¿Quiénes se benefician con el ensanchamiento de los mercados, y quiénes pueden participar en él desde las economías y culturas periféricas y cuántos quedan descolgados de los circuitos globales? Para García Canclini, las nuevas fronteras de la desigualdad separan cada vez más a quienes son capaces de conectarse a redes supranacionales de quienes quedan arrinconados con sus reductos locales.

¿Y que papel juega el lenguaje en todo esto? Este autor nos dice:

Si hablo de globalizaciones imaginadas no es sólo porque la integración abarca a algunos países mas que a otros. O porque beneficia sectores minoritarios de esos países y para la mayoría queda como fantasía. También porque EL DISCURSO GLOBALIZADOR recubre fusiones que en verdad suceden, como dije entre pocas naciones.

Explica también cómo las sociedades se abren para la importación y exportación de bienes materiales de un país a otro, y para que circulen MENSAJES coproducidos desde varios países QUE EXPRESAN EN LO SIMBÓLICO procesos de cooperación e intercambios, por ejemplo músi- 
cas y tecnologías, que aspiran a incorporar a todos; la educación generalizada y la extensión de beneficios modernos tanto en los países centrales como en los periféricos, en las élites y el pueblo. Sin embargo, en la realidad existe marcada distancia entre LOS DISCURSOS HUMANisTicos y las prácticas políticas. El actual proyecto modernizador no abarca a todos. Su selectividad se organiza según la capacidad de dar trabajo al menor costo y conquistar consumidores más que desarrollar a la persona. La competencia y la discriminación del mercado prevalecen sobre la universalidad de derechos políticos y culturales. Por tanto, aún cuando en estos días se habla de la integración entre países latinoamericanos y otras regiones del mundo, y se realizan acuerdos, la apertura a los otros, la construcción de una interculturalidad democrática, está más subordinada al mercado que en cualquier otro tiempo. ${ }^{5}$

4. Aunque el enfoque matemático del lenguaje ya reconocía las dimensiones semánticas y sintácticas del idioma, no fue sino hasta la primera mitad del siglo xx cuando Ludwig Wittgenstein, con su giro lingüístico, sentó las bases para la investigación sobre la dimensión pragmática del idioma en la que se reconoce que el lenguaje es un juego cuyo significado depende de una comunidad, fuera de la cual, este juego puede ya sea no ser totalmente comprendido, puede ser malinterpretado o en el peor de los casos ser manipulado para un intercambio lingüístico desigual. ${ }^{6}$

Tal aporte ha resultado en una innumerable secuencia de investigaciones sociolingüistas que crecientemente apuntan hacia elaboraciones teórico-prácticas que no sólo influyan positivamente al respeto intercultural y promuevan la tolerancia mutua, sino que también resulten en nuevos diseños curriculares que incorporen enfoques, métodos, técnicas y procedimientos específicos de la enseñanza de idiomas en general y que exigen un protagonismo más responsable y una modificación en el perfil de los profesores de inglés, quienes hemos participado en la expansión de dicha lengua como facilitadores de su adquisición y aprendizaje, y quién sabe si como colaboradores involuntarios al crear un vasallaje para los actuales dirigentes del mundo neoliberal, los que en su mayoría hablan el inglés perfectamente.

El enfoque pragmático-funcional actual de una visión gramatical moderna comunicativa reconoce tres aspectos en los que la gramática 
[comunicativa-interactiva] es funcional (pragmática). Invito al lector a preguntarse si en la cotidianidad estos aspectos se llevan a cabo equitativamente o si hay escondidas entre ellos relaciones desiguales de poder.

\section{Las metafunciones del lenguaje ${ }^{7}$ a las que identifica como:}

1.a. La función representacional o simbólica, que tiene como propósito del emisor el exponer su visión o entendimiento propio del mundo a fin de incidir en la perspectiva del receptor con el propósito de modificar el medio ambiente que le rodea desde esa visión individual.

1.b. La función interpersonal, que indica la transacción interactiva y negociadora que en su efecto peyorativo, podría resultar en la manipulación o servilismo entre los participantes.

1.c. La función textual, que comprende los códigos de la comunicación ya sean los distintos modelos retóricos de organización de los diferentes idiomas del mundo, así como los dispositivos de cohesión que posibilitan el intercambio lingüístico.

2. Los patrones habituales de diferentes clases que ayudan a distinguir entre los usos para los que sirve un idioma. Estos pueden resumirse en:

2.a. Patrones estructurales, que se identifican con los tipos de conducta social

2.b. Grupos nominales, que proveen información sobre entidades

2.c. Categorias sintácticas representativas de la noción de funciones del lenguaje

3. La funcionalidad gramatical que puede resumirse asi: "Cada elemento lingüístico visto en relación con los otros." "Cada uno... tiene el potencial de realizar diferentes funciones." Los hablantes están en libertad de optar por los patrones que "mejor lleven a cabo sus propósitos comunicativos a fin de llevar a cabo las funciones de representación, la interpersonal y la textual en cada momento de su interacción con otros."

Es en este contexto y con estas premisas en mente que cabe preguntarse sobre el intento imperialista lingüístico del idioma inglés, las 
reacciones encontradas no sólo ante tal acusación sino en la expansión del idioma inglés mismo y, muy especificamente, qué papel jugamos los profesores de inglés en toda esta red que disputa la autonomía o la subyugación lingüistica.

\section{El idioma inglés en el contexto global actual ${ }^{4}$}

Procedamos sin más a comparar las posiciones antagónicas y las investigaciones hechas sobre el idioma inglés en un contexto global. Para ello, consideraremos las opiniones de los especialistas Randolph Quirk y de Braj Kachru sobre la posibilidad y la conveniencia de promover un sólo estándar del inglés con el objetivo de mantener la mutua inteligibilidad del inglés como un medio de comunicación internacional, seguidas por los comentarios de Graeme Kennedy y David Crystal, sobre los planteamientos de Quirk. A continuación, resumiré las ideas principales vertidas por Boyle sobre el imperialismo lingüístico y las actitudes internacionales ante el fenómeno de la expansión del inglés como idioma mundial. Dejo al libre criterio del lector el establecer algunas similitudes entre tales posiciones y lo expuesto en las visiones teóricas generales.

\subsection{Randolph Quirk}

Quirk representa fielmente a los defensores y promotores de la estandarización o imperialismo lingüístico mundial del inglés. Para comenzar su argumento, hace alusión a una de las declaraciones más conocidas a su favor contenida en The Arte of English Poesie (El arte de la poesia inglesa), en 1589, en donde se afirma que una forma determinada del inglés es micho más apreciada que todas las demás. En el texto se exige adoptar "el habla usual de la corte, y la de Londres y el de sus condados próximos, y no más allá. Ninguna variedad del inglés es $\tan$ distinguida ni tan actual". Al reconocer la diferencia entre ese tiempo en el cual el inglés era de uso exclusivo para los hablantes nativos y el actual en el que menos de la mitad de sus hablantes son nativos y sin embargo es el idioma más utilizado alrededor del mundo, Quirk divide a los hablantes del inglés en tres grupos, a saber: EFL (inglés como idioma extranjero), ESL (inglés como segundo idioma) y ENL (inglés como idioma natal) El primer grupo está formado por individuos que "viven en países que necesitan el inglés para (...) pro- 
pósitos 'externos': contactos con personas en otros países (...), con fines de comercio o desarrollo científico (...) cuyo uso del inglés no está restringido a países de habla inglesa: Un coreano manufacturero del acero usará el inglés al negociar con una firma en Brasil". El segundo grupo, ESL, lo identifica con las regiones en donde el inglés es ampliamente utilizado con propósitos internos de administración, difusión, y educación, entre otros. Casualmente, no consideró importante mencionar que estas regiones han sido, casi exclusivamente, colonias subyugadas por potencias de habla inglesa, con las nefastas consecuencias políticas, económicas, sociales, culturales y de violación a su autonomía que el colonialismo conlleva. En el tercer grupo, ubica a los países como Inglaterra y los Estados Unidos en los que el inglés es el idioma natal.

Ante tal diversidad, Quirk nos recuerda que al igual que en la antigüedad "estamos regulados por los diccionarios de inglés y por otros libros escritos por hombres letrados". Y aunque reconoce el énfasis actual puesto en la multiplicidad y variabilidad de estándares de acuerdo a ocasiones diferentes para pueblos diferentes, cada una tan correcta como la otra, cree que sería un error el sobredimensionar las diferencias entre el tiempo de Shakespeare y el actual. Niega la posibilidad de que el inglés se convierta en idiomas distintivos, como sucedió con el latín que ahora se presenta en idiomas tan distintos como el francés, el español, y el italiano. Ya en tiempos de Shakespeare se reconocía la variedad y variabilidad del inglés. Quirk cree que en parte, el problema ha radicado en no establecer los aspectos del inglés a ser estandarizados. Se creyó que el léxico debía estandarizarse en oposición a los dialectos, que había una gramática estándar, que sobre todo había una ortografía estándar. Menos susceptible a estandarización fue la pronunciación, la que con el adelanto en los medios de comunicación se hizo más patente; ante lo cual se generalizó un estándar. En los Estados Unidos se eligió la pronunciación de la población culta intermedia a la que se refirió como network English (Inglés de red). En el Reino Unido se eligió la voz minoritaria de las escuelas públicas $(\mathrm{RP}=$ Received Pronunciation) a la que frecuentemente se hizo referencia como $\mathrm{BBC}$ English. Esto estandarizó solamente a dos pronunciaciones minoritarias, la de los Estados Unidos y la del Reino Unido, lo que implicó, en el caso del inglés, de que el idioma estándar sea inevitablemente la prerrogativa de una minoría marcadamente especial. 
Mientras tanto, a comienzos del siglo XX se llevó a cabo otra innovación: LA FNSFNANANZA PROFFSIONAL DFL INGLÉS para quienes no era su idioma natal, la que en sus inicios fue una actividad británica en la que solamente se enseñaba la pronunciación RP o BBC. Con el pasar del tiempo, y aun cuando Quirk no lo menciona, al decaer el imperio británico y "ceder" su espacio al norteamericano (los Estados Unidos de América) , el estándar estadounidense fue ganando terreno. La supremacía de ambos estándares del inglés demuestra para Quirk que una variedad letrada, universalmente aceptada puede ser descrita como una unidad. Es más, con la creciente dependencia a una tecnología común cuyo desarrollo está primordialmente en manos de las corporaciones multinacionales, la preservación de la intercomprensibilidad, que para Quirk posibilita el criterio de estandarización determinado por las minorías debería de ser un deseo mundial. Quirk cree que de hecho existe una necesidad de los estándares (ya sea en la moral, la conducta sexual, el vestir, el buen gusto). Cree que es un rasgo endémico de nuestra condición mortal y que las personas se sentirían desorientadas si este no existiera. Y en el caso del estándar del inglés, el número relativamente limitado de propósitos para los que las necesidades de los hablantes no nativos usan el inglés, exige una forma estándar que se vea y oiga tan bien hablada como escrita y que sea entendida y respetada en todas las partes del planeta.

\subsubsection{Comentario 1. Graeme Kennedy}

Kennedy compara la posición de Quirk a la de Clifford Prator quien en 1968 llamó "La herejía británica en TESL (siglas en inglés para la enseñanza del inglés como segundo idioma), señalando que la aceptación y el apoyo a las variaciones locales del inglés por los británicos resultaban en detrimento para la comunicación global.

Para Kennedy, los asuntos relacionados con los estándares en los países en donde el inglés es el idioma natal es fundamentaimente un asunto de actitud y estética. Los estándares emergentes pertenecen a los grupos de poder y de prestigio en la economía, el entretenimiento, los medios de comunicación, las artes y demás.

Kennedy no deja de lado la pregunta sobre la inteligibilidad, lo que se vuelve cada vez más difícil al sobrepasar los límites de la familiari- 
dad aprendida para un rango limitado de funciones del idioma segundo y especialmente extranjero.

En alusión a la posición de Quirk sobre "el número relativamente limitado de propósitos para los que las necesidades de los hablantes no nativos usan el inglés", Kennedy demuestra que un estudio detallado sobre el uso del inglés por los hablantes no nativos ha revelado una amplia complejidad en alcance, uso y propósitos. Y enfatiza que lo que realmente interesa no es una élite minoritaria, sino el uso del idioma que la vasta mayoría de usuarios del inglés le da. En tal sentido, más importante que el tan aclamado estándar deberá ser una cultura popular internacional para determinar las normas a seguir independientemente de si tienen o no sanciones educativas u oficiales. Esto debería ser así, puesto que la mayoría de usuarios del inglés tienden a adoptar variedades locales del idioma independientes de las amonestaciones de los profesores de inglés, amonestación que inclusive en los países ENL, han tenido como efecto primario la humillación en lugar de un cambio de conducta.

Kennedy finaliza su comentario con la siguiente pregunta: Aún cuando se puedan adoptar y promover estándares del inglés, ¿pueden estos influenciar significativamente las direcciones en que se mueve y usa el inglés en un contexto mundial?

\subsubsection{Comentario 2. David Crystal}

He decidido traducir casi textualmente este comentario a fin de evitar omitir cualquier dato esencial de su ponencia.

Estoy muy de acuerdo con el énfasis que el profesor Quirk da al estándar del inglés. Estoy seguro de que este es el núcleo del asunto. Lo que me preocupa, sin embargo, es la forma en que toda la discusión de los estándares deja rápidamente de ser una discusión lingüística y se vuelve un asunto de identidad social, y echo de menos esta perspectiva en su ponencia. Los orígenes sociales de la noción de 'estándar' son evidentes en las definiciones del término en los diccionarios, verbigracia, 'algo establecido por la autoridad, la costumbre o el consentimiento general como un modelo o ejemplo' (Diccionario Longman del idioma inglés). De hecho, la sociedad le confiere o sanciona estatus al estándar de algo, como bien lo indica Quirk, y por eso adquiere el sentido secundario de 'un gra- 
do de cualidad o de valor' que en retorno resulta en los usos peyorativos de 'no estandarizado' y 'sub-estandarizado' El término renueva su conexión con la sociedad cuando hay discusiones sobre su uso, aunque frecuentemente las suposiciones sociales permanecen bajo la superficie. Por ejemplo, a nivel local, los argumentos utilizados por los profesores al corregir el inglés escrito de un niño son generalmente formulados en términos puramente lingüísticos: No deberías usar ain 't - ¿Por qué? -porque no es un inglés estandarizado. Pero esto identifica el problema, no lo explica, y cualquier pregunta del tipo "¿Por qué tengo que escribir / hablar inglés estándar?" resulta inevitablemente en un razonamiento social (la necesidad de pasar exámenes, para conseguir un trabajo, para calificar como miembro de una sociedad, etc.).

El mismo principio es válido globalmente, sólo que ahora la cuestión de la identidad se vuelve más difícil. Considere la gama de posibilidades que pueden ser usadas para completar el espacio en la clase de pregunta que podría utilizar un psicólogo: "Si él habla inglés, él debe ser/ o estar ". Dependiendo de donde viva, la respuesta será "Británico/ Americano/ un imperialista/ un enemigo/ uno de los opresores/bien educado/ un diplomático/ un extranjero/ rico/ tratando de impresionar/ de buen humor..." Existe una larga lista de posibles respuestas y no todas son placenteras. La conferencia intenta evaluar el progreso en los estudios del inglés, en cuyo caso no debemos olvidar esas áreas donde la expansión del inglés es una mala noticia, y donde la gente tiene una actitud antagonista hacia el idioma, por una variedad de razones sociales, económicas o políticas. Por ejemplo, ¿Cómo se llenará el espacio en las regiones francófonas del Canadá, o en partes de Gales, Escocia e Irlanda, o en ciertos grupos africanos del Sur y del Occidente? ¿O en cualquier región en donde las políticas de planeamiento están teniendo que tomar seriamente las demandas de los grupos minoritarios? La pregunta no es tanto si la gente usa el inglés internacionalmente sino, cen qué estado de ánimo, con qué actitud lo usan? ¿Están orgullosos de ello, o avergonzados? ¿Lo ven como una fortaleza o como una debilidad? ¿Con quién se identifican cuando lo usan, y estarán orgullos de tal identificación?

Por supuesto que estas preguntas pueden aplicarse a cualquier variación del idioma, así como al idioma en su conjunto. Por lo tanto 
debemos preguntarles sobre el RP, Network American, o cualquier otra variación regional o de clase. Debemos preguntarles sobre el inglés estandarizado en Inglaterra, como lo señaló el profesor Quirk. Ante todo, necesitamos preguntarles sobre el "único estándar monocromático", que es el tema de su conferencia. Todas estas preguntas, en efecto, se reducen a una: ¿No debería la visión cuantitativa del inglés en el mundo ser complementada por una rigurosa visión cualitativa - una visión pragmática o ergonómica- (...) en la que se reconocieran niveles de aceptación, aquiescencia y antipatía entre los que han llegado a usar el idioma; y al final, ino es esta visión de mucha mayor importancia para los involucrados en el mundo de la enseñanza del inglés y en la investigación que una simple toma de conciencia de la unidad y expansión del idioma estándar? Yo veo dos preguntas acá. Sin embargo, permítanme reducirlas a una. El párrafo final del profesor Quirk comenzaba: "The English language works pretty well in its global context today (El idioma inglés funciona muy bien en su contexto global ahora)". Mi pregunta deviene de la clase de punto de vista sociolingüístico que he estado señalando, y es simplemente esta: ¿Qué tan pretty es pretty?

\subsection{Braj Kachru}

El propósito del discurso de Kachru es el de discutir algunas de las implicaciones de la difusión global del inglés, con un enfoque particular en las cuestiones de la estandarización y la codificación de la creatividad e innovaciones lingüísticas en sus variedades institucionalizadas no nativas. En su discurso señala que las investigaciones realizadas, especialmente después de la década de 1950, proveen cierta perspectiva de la difusión internacional del inglés, de las actitudes hacia ella y hacia otros idiomas de amplia comunicación, de sus características formales y funcionales, y de su impacto en los idiomas mundiales principales. Estas han proporcionado estudios de casos, tanto de la nativización del inglés como de la anglización de otros idiomas mundiales. Al mismo tiempo invita a profundizar en las variadas razones actitudinales, teóricas, y logísticas. Actitudinalmente, señala que hay un conflicto entre las normas lingüísticas percibidas y la conducta real del idioma. Teóricamente, muchos lingüistas siguen condicionados por un modelo monolingüista para la descripción y el análisis lingüístico y 
aún deben proporcionar un marco de referencia y una metodología descriptiva para la descripción y el análisis del uso bilingüe o multilingüe del lenguaje y la creatividad lingüística. En términos logísticos, dice que tal investigación implica un arduo trabajo empírico en un esfuerzo conjunto de investigadores que sean tanto multilingües $y$, en algún grado, multiculturales. Esta tarea se vuelve mucho más compleja, debido a la inigualable magnitud de la expansión del inglés, a las variedades de contextos globales en los que el inglés es utilizado y a las motivaciones variadas para su adquisición y uso en las regiones anteriormente coloniales luego de la fase política del período colonial. Ante estos hechos, y con el resultado de las innovaciones locales al inglés, pareciera que no existe un estándar universalmente aceptable.

Kachru estratifica el uso del inglés en tres grandes círculos: el interno, el externo o extendido y el círculo en expansión, los que guardan una estrecha concordancia con los identificados por Quirk como ENL, ESL y EFL, respectivamente, con la marcada diferencia que Kachru si incluye las dimensiones sociolingüísticas pertinentes que representan a los tipos de expansión, a los patrones de adquisición y a los dominios funcionales-pragmáticos en los que se usa el inglés a través de las culturas y los idiomas.

El círculo interno se refiere a las bases tradicionales del inglés. El círculo externo requiere de una explicación histórica: envuelve fases anteriores de la expansión del inglés y su institucionalización en contextos no nativos, en los que la institucionalización de dichas variedades tienen explicaciones lingüísticas, políticas y socioculturales fuertemente caracterizadas por extensos períodos de colonización, con resultados buenos y malos, los que no se puede simplemente desear que desaparezcan.

El círculo en expansión le da al inglés aún otra dimensión. Estas regiones no tienen necesariamente una historia de colonización, y es el círculo que más rápidamente se está extendiendo, resultando en innumerables variaciones de actuación lingüística del inglés. Este círculo envuelve a poblaciones tan grandes como la China y Japón (con poblaciones de $1,015,410,000$ y $119,420,000$ de habitantes en 1984) y tan pequeñas como la nuestra, por lo que no puede verse claramente demarcada una de la otra. Muchos y variados han sido los factores para la difusión del inglés en este círculo. Entre ellos predominan varios factores políticos y sociolingüísticos. Un dato curioso que men- 
ciona Kashru es el hecho de que en el sentido sociolingüístico, un número considerable de estos países cae en la categoría de países en vía de desarrollo, en los que las necesidades del uso del inglés son en gran parte determinadas por consideraciones de modernización, comercio y acceso a tecnología. Puesto que estas regiones están en su mayoría alejadas del círculo interno, esto tiene serias implicaciones para el aprendizaje y la enseñanza del inglés. Muchas de estas naciones difieren considerablemente en sus religiones, creencias, patrones culturales, y sistemas políticos de los países del círculo interno. Tal parece que la difusión del inglés (por sí sola) tolera cualquier sistema político. Por ejemplo, en Asia del Sur, lo usan tanto los marxistas, los musulmanes fundamentalistas, los defensores de los derechos humanos y hasta varias fracciones del Congreso. Lo que une a estos grupos es el valor que le dan al inglés para fomentar sus respectivos fines políticos.

La variedad y riqueza cultural de estos tres círculos le da al inglés un pluralismo cultural único y una heterogeneidad y diversidad lingüística nunca antes vista en la historia de la humanidad de la cual resultan los problemas concernientes a la codificación, la estandarización, la nativización, la enseñanza, la descripción y por supuesto, la multitud de actitudes sobre el reconocimiento de varias variaciones y subvariaciones del inglés.

Como consecuencia, Kashru propone que a fin de responder a las implicaciones teóricas, aplicadas y actitudinales, el prescriptivismo debe estar basado en el realismo y el pragmatismo lingüístico. Es decir que debería ser más descriptivo. Esto nos lleva al concepto de "comunidad de hablantes del inglés" para el que sugiere un cambio al término speech partnership (cuya traducción más cercana sería la confraternidad del habla), retomado de Firth, quien lo sugirió en el año de 1959. Este cambio es necesario puesto que el término comunidad de hablantes ha adquirido una connotación normativa o prescriptiva; mientras que speech fellowship nos acerca más al mundo real de los usuarios del inglés. Kashru subraya la necesidad de cambiar a este término puesto que los no nativos que usan estos speech fellowships están usando los ingleses del mundo en sus situaciones y contextos divergentes, y con varias actitudes étnicas y lingüísticas. Al explicar el énfasis hecho en las palabras en negritas que preceden, Kashru explica: Situaciones que incluyen la ecología lingüística, política, sociocultural y económica; 
contextos que se refieren a los roles de los participantes en estas situaciones y su apropiada adaptabilidad de las variedades del lenguaje utilizadas en estos roles. Por actitudes, entiende Kashru tanto las actitudes evidentes como las imperceptibles hacia un idioma, sus variedades, y los usos y usuarios de estas variedades.

Kashru sintetiza todo el debate suscitado por la expansión universal del inglés en cuatro preguntas que pueden ser esquemáticamente resumidas así:

\begin{tabular}{|c|c|c|}
\hline PREGUNTA & $\begin{array}{c}\text { AREA DE } \\
\text { CONSIDERACION }\end{array}$ & IMPLICACIONES \\
\hline $\begin{array}{l}\text { Quién controla las } \\
\text { normas? }\end{array}$ & $\begin{array}{l}\text { La codificación del } \\
\text { inglés }\end{array}$ & $\begin{array}{l}\text { En la actualidad no existen instituciones } \\
\text { reguladoras, como ocurre en el castellano, con } \\
\text { la Real Academia Espanola. } \\
\text { Entre los canales reguladores están los diccio- } \\
\text { narios, las actitudes sociales, las preferencias } \\
\text { educativas y la discriminación laboral basada } \\
\text { en el acento. }\end{array}$ \\
\hline $\begin{array}{l}\text { ¿Qué tipos de inno- } \\
\text { vaciones y de crea- } \\
\text { tividad son acepta- } \\
\text { bles? }\end{array}$ & $\begin{array}{l}\text { Las desviaciones de } \\
\text { las normas }\end{array}$ & $\begin{array}{l}\text { Puesto que las aparentes desviaciones no de- } \\
\text { ben ser apartadas de sus funcines, ahora se } \\
\text { discute sobre las transferencias entre idiomas, } \\
\text { entre las que sobresalen tres tipos de variacio- } \\
\text { nes del inglés: Acrolect ocultas, Mesolect o } \\
\text { semicultas y Basilect o incultas } \\
\text { Las que resultan en colocaciones, hibridacio- } \\
\text { nes, expresiones idiomáticas y construcciones } \\
\text { comparativas. }\end{array}$ \\
\hline $\begin{array}{l}\text { ¿Cuáles son los fac- } \\
\text { tores que determi- } \\
\text { nan la norma para } \\
\text { una región? }\end{array}$ & $\begin{array}{l}\text { El pragmatismo de } \\
\text { la selección de nor- } \\
\text { mas }\end{array}$ & $\begin{array}{l}\text { Amplios estudios se han realizado sobre el } \\
\text { tema puesto que el inglés ha desarrollado aún } \\
\text { sus variaciones inherentes nativas en países } \\
\text { como Australia y los Estados Unidos. }\end{array}$ \\
\hline $\begin{array}{l}\text { ¿Cuales son los } \\
\text { parámetros para la } \\
\text { aculturación del in- } \\
\text { glés }\end{array}$ & $\begin{array}{l}\text { La desanglización del } \\
\text { contexto cultural } \\
\text { del inglés en las va- } \\
\text { riaciones no nativas } \\
\text { (creatividad bilin- } \\
\text { güe) }\end{array}$ & $\begin{array}{l}\text { Esto implica la dinámica interrelación existen- } \\
\text { te entre el lenguaje y la cultural. } \\
\text { En la mayoria de innovaciones existe una cla- } \\
\text { ra relación entre los patrones lingüisticos del } \\
\text { texto, la transferencia de estrategias cultural- } \\
\text { mente subyacentes y de los efectos cultural- } \\
\text { mente deseados. }\end{array}$ \\
\hline
\end{tabular}

Para finalizar, Kashru reflexiona sobre los modelos y métodos usados en las investigaciones sobre las variedades del inglés y llama a cuestionarse si hasta hace recientemente no son sino paradigmas dominantes los que han prevalecido en las investigaciones. Hace referencia a nuevos paradigmas que han entrado en escena como son los modelos de contextualización, de interacción y el de variación. Esto lo 
Lleva a poner su mirada en la profesión de la enseñanza de idiomas TESL y TEFL, enseñanza del inglés como segundo idioma y como idioma extranjero, respectivamente. Ante lo cual incita a quienes estamos envueltos en este ejercicio a darnos cuenta de las responsabilidades globales ante las que nos enfrentamos en este contexto del inglés globalizado. Enfatiza que la actitud de avestruz de esconder la cabeza en lo que considera un hoyo seguro ante el riesgo / peligro y pretender que no sucede nada, no responde a la ecología internacional actual del inglés. Lo que se necesita es un cambio de actitud y un verdadero profesionalismo basado en el pragmatismo lingüístico y el realismo; y señala que aunque se hagan esfuerzos por hablar de los estándares, no podemos seguir ignorando la realidad socio-lingüística de los usuarios de cada speech fellowship.

\subsection{Joseph Boyle}

De las conferencias dictadas por Joseph Boyle, me limitaré a resumir la noción del imperialismo lingüístico y sus rasgos principales.

Boyle señala como en los últimos veinte años el inglés se ha convertido en la lengua franca del mundo por servir como el medio común entre las personas con idiomas nativos diferentes, a pesar del comprensible resentimiento de algunos ante la aparente arrogancia lingüística de las naciones poderosas de habla inglesa, las que en su mayoría tienden a tomar por sentado que son los otros los que tienen que hablar su idioma, el inglés, en las comunicaciones internacionales.

Los que defienden el estatus multinacional del inglés lo ven como una fuerza positiva para el entendimiento internacional en un mundo dividido. Sus críticos ven en el inglés una herramienta neoimperialista de las multinacionales íntimamente asociada al poderío empresarial y militar angloamericano y a su implacable expansión mundial que destruye los idiomas y las culturas locales. Es un idioma que se adapta tan bien a los intereses del comercio internacional que debe expandirse globalmente para hacer más fácil y efectiva la comercialización. Para el sector comercial, la expansión del inglés fortalece su control global e incrementa sus ganancias en general, y, además, su misma exportación ofrece oportunidades económicas tales, que una de las industrias prósperas de Gran Bretaña es la enseñanza del inglés, al dejar ganancias de más de $\$ 3$ billones al año. Considerando que la demanda se amplía cada día, un mercado de tal magnitud es claramente atractivo. 
Dichas motivaciones económicas se revisten engañosamente como una forma altruista de ayudar a los países menos desarrollados para que lleguen a formar parte de la actividad empresarial y mejoren sus condiciones. Tal como Noam Chomsky señala, es el sector empresarial el que efectivamente dirige a las sociedades capitalistas modernas y es su compromiso fundamental el de utilizar el mercado global de tal forma que le proporcione la ganancia máxima, al mismo tiempo que "presente su compromiso como si estuviera guiado por una profunda preocupación por el bienestar humano."10

En un libro titulado Imperialismo lingüistico, escrito por Phillipson en $1992^{\prime \prime}$, se señala que el idioma inglés y el negocio de la enseñanza del mismo alrededor del mundo perpetúan un sistema de neoimperialismo al apoyar un sistema global del comercio mundial que le da ventaja a los países centrales (ricos y poderosos) y desventajas a los periféricos (países más pobres). Según Phillipson, el imperialismo lingüístico sigue tres etapas: 1 . La presencia de los colonizadores y la imposición de su lenguaje, 2. La formación de la élite local, competente en el lenguaje del colonizador, la cual actúa como un puente político y comercial y 3 . La etapa de la persuasión ideológica, a través del uso de los medios y de la tecnología. Phillipson también distingue entre el paradigma de la difusión del inglés, caracterizado por el capitalismo triunfal, su ciencia y su tecnología y una visión monolingüe de la modernización y de la internacionalización, y por otro lado, coloca el paradigma de la ecología del lenguaje que promueve la construcción de una diversidad lingüística mundial, la promoción del multilingüismo y el aprendizaje del inglés con la concesión de derechos humanos lingüísticos a los hablantes de todos los idiomas."

El primer paradigma pone en peligro la diversidad cultural y lingüística. El segundo ofrece una solución parcial al dilema de la identidad individual versus la inteligibilidad mutua, al sugerir la noción de las variedades del inglés.

Independientemente de la posición que se adopte sobre el tema del imperialismo lingüístico y el idioma inglés, en principio pareciera ser que con el aprendizaje del inglés viene inevitablemente impuesta su cultura, directa o indirectamente. Sin embargo, al igual que ante la aparentemente inevitable puesta en marcha de las políticas neoliberales, pareciera que no hay nada más que aceptarlas sumisa y rastreramente, siempre quedan abiertas a la opción creativa y rechazarlas de manera 
innovadora, al hacernos cargo activa y responsablemente de nuestro futuro y elaborar propuestas alternativas que se les opongan.

\section{Notas}

1. Brown, D. 1994. Teaching by Principle,. p. 3 New Jersey: Prentice Hall Regents

2. Quirk, R and H. G. Widdowson (Editors). 1985. English in the World. Teaching and Learning the Language and Literatures. Pág. 9. Cambridge: Cambridge University Press

3. Bourdieu, P. 1999. Contrafuegos, p. 44. Barcelona

* Hay que diferenciar este uso del vocablo pragmatismo, de la categoría de pragmatismo utilizada para designar el área prácrica descriptiva del uso del lenguaje como juego lingüístico.

4. Galeano, E. 1998. Patas Arriba, pp. 41-42 México

5. García Canclini, N. 2000. La globalización imaginada. México

6. Conferencia impartida por la autora en el primer congreso de profesionales en la Enseñanza de Idiomas Extranjeros en Octubre de 2001 en la Universidad de El Salvador.

7. Downing, A, and P. Locke. 1995. A University Course in English Grammar. P. xi, xiii. London: Phoenix ELT.

8. Ídem. Downing, p. xii

9. Quirk, R and H. G. Widdowson (Editors). 1985. English in the World. Teaching and Learning the Language and Literatures. Pp. 1-34. Cambridge: Cambridge University Press

* Hago esta distinción, puesto que suficiente controversia ha suscitado el término americano, como si fuera propiedad exclusiva del pueblo de los Estados Unidos de América, controversia que ha resultado en una denominación opcional de norteamericanos o Norteamérica, soslayando el hecho de que tanto México como Canadá son también norteamericanos.

* Citado anteriormente, al inicio del ensayo

* Remarco la palabra pretty, puesto que su traducción textual no tiene la misma connotación que Crystal trata de resaltar. Pretty no es utilizado solamente como un adverbio enfático, sino que su uso más común significa bonito.

10. Noam Choamsky. 1982. Towards a New Cold War. London, Sinclair Browne

11. Phillipson R. 1992. Linguistic Imperialism. Oxford University Press. 